\author{
ARTIGO \\ dO https://doi.org/10.22481/praxisedu.v15i36.5929
}

\title{
THE INTERCONNECTION OF INHIBITORY CONTROL AND THE INTERNAL PICTURE OF HEALTH IN PRIMARY SCHOOLCHILDREN
}

\author{
LA INTERCONEXIÓN DEL CONTROL INHIBITORIO Y LA IMAGEN INTERNA DE \\ LA SALUD EN LOS ESCOLARES DE PRIMARIA
}

\begin{abstract}
A INTERCONEXÃO DO CONTROLE INIBITÓRIO E O QUADRO INTERNO DA SAÚDE EM ESCOLARES DO ENSINO FUNDAMENTAL
\end{abstract}

V.S. Merenkova

Bunin Yelets State University - Russia

O.E. Elnikova

Bunin Yelets State University - Russia

\begin{abstract}
We supposed that a person's health-conscious attitude, when actualized in a specific action must be connected to certain objective psychophysiological characteristics, for example, to inhibitory control. The aim of the present research was to study the interrelation of the inhibitory control and the internal health picture (further referred to as IPH) in primary schoolchildren. We examined 72 primary schoolchildren (mean (SD) age: 10.3 (0.9) years). Inhibitory control was assessed by the ReBOS tool (Vergunov, Nikolaeva, 2018). The IPH level was measured by a questionnaire (Nikolaeva et al., 2014). It was found that the higher IPH level boys have, the better they control their actions. The way girls respond to participating in an activity is directly related to their IPH development. But unlike the data obtained in the boys' group, the girls' inhibitory control is not related to their IPH level.
\end{abstract}

Keywords: inhibitory control, internal picture of health, primary schoolchildren, boys and girls.

Resumen: Supusimos que la actitud consciente de la salud de una persona, cuando se actualiza en una acción específica, debe estar conectada a ciertas características psicofisiológicas objetivas, por ejemplo, al control inhibitorio. El objetivo de la presente investigación fue estudiar la interrelación del control inhibitorio y el cuadro de salud interna (también denominado IPH) en los escolares de primaria. Examinamos 72 escolares de primaria (edad media (DE): 10,3 $(0,9)$ años). El control inhibitorio fue evaluado por la herramienta ReBOS (Vergunov, Nikolaeva, 2018). El nivel de IPH se midió mediante un cuestionario (Nikolaeva et al., 2014). Se descubrió que cuanto mayor es el nivel de IPH que tienen los niños, mejor 
controlan sus acciones. La forma en que las niñas responden a participar en una actividad está directamente relacionada con su desarrollo de IPH. Pero a diferencia de los datos obtenidos en el grupo de niños, el control inhibitorio de las niñas no está relacionado con su nivel de IPH.

Palabras clave: control inhibitorio, imagen interna de la salud, escolares primarios, niños y niñas.

Resumo: Supomos que a atitude consciente da saúde de uma pessoa, quando realizada em uma ação específica, deva estar conectada a certas características psicofisiológicas objetivas, por exemplo, ao controle inibitório. O objetivo da presente pesquisa foi estudar a inter-relação do controle inibitório e do quadro interno de saúde (mais conhecido como IPH) em escolares do ensino fundamental. Foram examinados 72 escolares do ensino fundamental (idade média (DP): 10,3 (0,9) anos). O controle inibitório foi avaliado pela ferramenta ReBOS (Vergunov, Nikolaeva, 2018). O nível de IPH foi medido por um questionário (Nikolaeva et al., 2014). Verificou-se que quanto mais alto o nível de IPH, maior o controle sobre suas ações. A maneira como as meninas respondem à participação em uma atividade está diretamente relacionada ao seu desenvolvimento de IPH. Porém, diferentemente dos dados obtidos no grupo dos meninos, o controle inibitório das meninas não está relacionado ao seu nível de IPH.

Palavras-chave: controle inibitório, quadro interno de saúde, escolares, meninos e meninas.

\section{Introduction}

The identification of factors affecting children's and teenagers' health is a critically important field of research which provides information about the measures needed for health formation, health improvement and maintenance throughout a person's life. In recent years, executive functioning has been seen as one of the factors that can strongly influence children's and adolescents' health (Nelson et al., 2019; Bernardi, 2019; Chistobaev et al., 2018; Al-Hashimy et al., 2019). Executive functioning is a set of upper-level cognitive processes needed for attention and behavior management (Diamond, 2013). These processes allow purposeful behavior, and are therefore vital in situations involving planning and decision making, or for inhibiting inappropriate behavior (Zysset et al., 2018). Though the characteristics of executive functions are found to be the best predictors of the quality of life (Diamond, 2013), it remains still unclear what factor is the main one. The functions of executive control in behavior management include three interrelated abilities: working memory (an ability to store information in the mind and work with it); inhibitory control (an ability to control attention, behavior, thoughts and emotions instead of acting on impulse or desire) and flexible shifting (an ability to switch between changing tasks) (Espy, 2016). 
The neuromechanisms regulating executive processes are mainly located in the prefrontal cortex and develop in the course of an individual's maturation (Diamond, 2013; Espy et al., 2011; Miyake et al., 2000). The review of literature showed that the preschool age is a critical period in the development of executive functions, and it is during this time that individual differences arise (Espy, 2016). A number of studies show that inhibitory control skills continue to develop in primary school (Garon et al., 2008; Rose et al., 2011), although relatively little is known about the peculiarities of their development at this time and in adolescence which is considered to be another important period for inhibitory control development (Nelson et al., 2019; Brydges et al., 2014; Meland et al., 2006; Lee et al., 2013; Kechter et al., 2019).

According to Nelson, for some years the deficiency of the mentioned skills has been thought to be the reason for poor academic performance and destructive behavior (Nelson et al., 2019). However, the possible negative effect of poor inhibitory control on children's and adolescents' health has only lately become a subject of systematic research. It was found that strong executive functioning is positively related to results later in life such as social interaction, career achievements, family harmony, and health. On the opposite, there was found evidence that strong executive functioning reduces the risk of externalizing behavior disorders, attention deficiency and psychotropic drugs abuse (Gatz et al., 2019; Eakin et al., 2004; Blair \& Razza, 2007; Young et al., 2009; Miyake et al., 2012). A large-scale 32-yearlong longitude study involving 1000 children born in the same year in the same place gives further proof to the above-mentioned interrelation. The research should be seen as a reliable one due to the fact that as much as $96 \%$ of the participants examined at the start of the study were found and examined at the end of the experiment (Sawyer et al., 2015). The findings show that those who had better inhibitory control between the ages of 3 and 11 (for example, they could wait for their turn more patiently, show stronger resistance to distractors, were more purposeful and less impulsive while carrying out a task) were more likely not to leave school early, not to smoke or take drugs (Moffitt, 2012). As adults, they had better physical fitness, i.e. were less likely to have excess weight or high blood pressure, or have unhealthy addictions. At 30, they had a higher salary and violated law less compared to those who had worse inhibitory control until the age of 11 . Their IQ, social class, home and family life were also better (Sawyer et al., 2015; Razumnikova \& Nikolaeva, 2019; Aron, 2011).

The fact that it takes a long time - from early childhood to adolescence - for executive functioning to fully develop offers certain possibilities to influence this process at 
critical periods as neural plasticity makes it possible to treat arising deficiencies (Baron et al., 2016). The potential health benefits of encouraging inhibitory control at critical periods of its development are, however, not quite clear at present (Nelson et al., 2019).

It is known that poor health is not only a result of genetic of physiological characteristics, but is largely determined by the person's lifestyle and attitude to one's own health (Diamond \& Lee, 2011; Nikolaeva et al., 1995). The person's inner attitude towards health has great potential for promoting healthy lifestyle and health-oriented behavior (Novik \& Ionova, 2007). That is why we believe that the concept of "an internal picture of health" (further referred to as IPH) can be applied to the discussed subject (Sirgy, 2012). This concept denotes one's attitude towards one's own health, this attitude being a system of the individual's selective connections with different health-promoting or health-threatening phenomena of the surrounding environment. It also includes a certain assessment of one's own physical and psychic state (Nekrasova, 1984). Thus, a developed IPH is an ability to be aware of, assess and correct one's own psychophysiological state, a steady self-control and management of one's health-related emotions, the knowledge and mastering of healthpreserving and health-developing skills, and their practical application. It is supposed that IPH increases a person's susceptibility to illnesses (Nikiforov, 2002; Nikolaeva \& Merenkova, 2013; Nikolaeva \& Merenkova, 2017).

The review of literature made us put forward a hypothesis that a conscious attitude towards one's own health, actualized in a specific action, has to be connected with a person's objective psychophysiological characteristics, for example, with inhibitory control. This assumption seems to be quite reasonable as forming an inner picture of health and managing it requires self-control. That is why it became the aim of this study to explore the interrelation between inhibitory control and primary schoolchildren's IPH levels.

\section{Materials and Methods}

For the research we examined 72 primary schoolchildren (mean (SD) age: $10.3(0.9)$ years) who study in state-funded comprehensive schools of Yelets, Lipetsk region. Among the children there were 37 girls and 35 boys.

The children's inhibitory control was assessed using a reflexometry tool ReBOS (developed by Vergunov) which can assess the parameters of both simple and complex sensorimotor reactions. To assess the simple sensorimotor reaction, a participant was asked to 
press the SPACE button on the computer keyboard every time a circle appears on the monitor. The button had to be pressed as quickly as possible. In go/no-go tasks (assessing a complex sensorimotor reaction and inhibitory control) it was required to press the SPACE button every time a circle of any color except for the red one appeared on the screen. In this way we assessed the complex sensorimotor reaction average time and the number of wrong reactions, i.e. reacting to red circles or missing non-red stimuli (Nikolaeva et al., 2014; Nikolaeva \& Yavorovich, 2013).

To learn the primary schoolchildren's IPH levels, we used a quick diagnostic method developed by Nikolaeva (modified by the author) (Vergunov et al., 2018). It consists of four blocks each representing an IPH structural component. Each block is designed as a set of questions the answers to which are recorded. The child is given two points for each correct answer, no points for wrong answers and is taken one point for connecting health to taking pills or seeing doctors. Thus, having 50 or more points indicate a high IPH level, having 4050 points means a medium IPH level, less than 40 indicate a low IPH level (Nikolaeva \& Merenkova, 2017).

The data were processed using the SPSS Statistics program (version 22).

\section{Results}

The results of the experiment showed almost equal figures for children having medium and low IPH levels (see Figure 1).

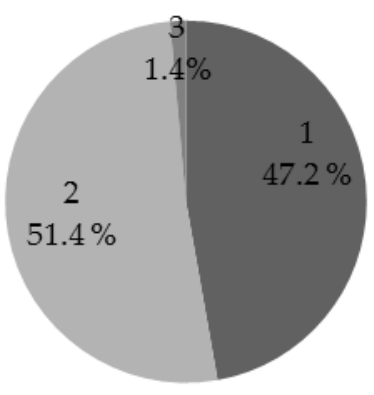

Note: 1=Low level of IHP; $2=$ average level of IHP; $3=$ high level of IHP

Figure 1: The distribution of children according to the IPH levels

At the next stage of processing the obtained data we carried out the factor analysis in each IPH group. Only one child was found to have a high IPH level, which made up $1.4 \%$ of the total number of participants. As no statistically valid data can be obtained from such an 
insufficient number of respondents, no factor analysis for a high IPH group was done. The factor analysis based on the principal component analysis with varimax rotation with Kaiser normalization in a low IPH group with a Kaiser-Meyer-Olkin coefficient equaling 0.590 and $64.8 \%$ of explained dispersion included two factors. The first factor is omissions during a complex sensorimotor reaction series. The second one shows an inverse relationship between wrong reactions to the stimuli and the average reaction time parameters: the shorter the reaction time is, the more wrong presses when seeing a No Pressing sign the child makes (see Table 1). This means that as soon as primary schoolchildren start rushing during a complex sensorimotor series, they control their actions worse thus making more mistakes.

Table 1: Rotation matrix of components in the factor analysis of the data collected from a group of primary schoolchildren having a low IPH.

\section{Inhibitory parameters}

Omissions in the first part of the complex sensorimotor .966 reaction test

Omissions in the second part

\section{control}

\section{Component} of the complex sensorimotor .943 reaction test

Average time in the first part of the complex sensorimotor - -.002 .876 reaction test

Average time in the second part of the complex -.095 .776 sensorimotor reaction test

Mistakes in the second part of the complex sensorimotor .256 $-.501$ reaction test

Mistakes in the first part of the complex sensorimotor .318 $-.460$ reaction test 
A different picture of the factor structure was found in the group having a medium IPH level (see Table 2).

Table 2: Rotation matrix of components in the factor analysis of the data collected from a group of primary schoolchildren having a medium IPH.

\section{Inhibitory parameters}

Omissions in the second part of the complex sensorimotor .942 reaction test

Mistakes in the second part of the complex sensorimotor .937 reaction test

Omissions in the first part of the complex sensorimotor .898 reaction test

Mistakes in the first part of the complex sensorimotor .864 reaction test

Average time in the first part of the complex sensorimotor .061 reaction test

Average time in the second part of the complex -.035 sensorimotor reaction test

\section{Component}

2

The factor analysis (Kaiser-Meyer-Olkin coefficient equaling 0.776 and $75 \%$ of explained dispersion) gave us two factors. The first factor with the largest weight includes mistakes and omissions made while doing the complex sensorimotor reaction test. The second factor with the largest weight included the average time of both in the simple and complex sensorimotor reaction tests. 
The analysis of the number of mistakes and omissions made by the children let us assess the degree of inhibitory processes development. The results we have obtained from examining the primary schoolchildren whose prefrontal cortex responsible for inhibitory control has not yet fully developed prove that doing a complex sensorimotor reaction test is directly connected to a sharp increase in wrong operations.

It should be said that the number of wrong presses - made when a No Pressing sign was shown - and of wrong omissions, i.e. not pressing the button when a circle of any color other than red was shown, does not depend on the average time in a complex sensorimotor reaction test, which means that reaction and inhibitory functions are regulated by different structures.

It should also be noted that the factor structure in medium and low IPH groups differs greatly, which serves as a reliability proof of the used questionnaire (Nikolaeva \& Merenkova, 2017).

Further we made an attempt to establish the inner principles of the interrelation between the inhibitory control parameters and IPH levels separately for the boys and the girls. The factor analysis (the coefficient of Kaiser-Meyer-Olkin equaling 0.591 and $82.88 \%$ of explained dispersion) produced three factors. The first factor includes the stimulus omissions in the complex sensorimotor reaction test; the second one includes a negative IPH level and mistakes with a positive sign. The third factor includes an average reaction time (see Table 3 ). The collected data show that the higher the IPH level is, the fewer mistakes the boys make, i.e. the better they control their actions.

Table 3: Rotation matrix of components in the factor analysis of the data collected from a group of primary schoolboys having different IPH levels.

\section{Inhibitory parameters}

Omissions in the second part of the complex sensorimotor .952 reaction test

Omissions in the first part of the complex sensorimotor

\section{Component}

123

3

$-.115$

.164

.097

.022 
reaction test

Mistakes in the first part of the complex sensorimotor

reaction test

Mistakes in the second part of the complex sensorimotor .515

reaction test

IPH level

Average time in the first part of the complex sensorimotor $-.027$ .904 reaction test

Average time in the second part of the complex -.046 sensorimotor reaction test

The factor structure was also obtained for the primary schoolgirls with different IPH levels. The explained dispersion was $69.2 \%$ with Kaiser-Meyer-Olkin coefficient equaling 0.525 and produced three factors. The first factor included stimulus omissions in both parts of the complex sensorimotor reaction test, the second one included mistakes. The third factor included the parameters of the average reaction time in the first part of the complex sensorimotor reaction test in the relation to the IPH levels.

Table 3: Rotation matrix of components in the factor analysis of the data collected from a group of primary schoolgirls having different IPH levels.

\section{Inhibitory parameters}

Omissions in the second part of the complex sensorimotor .885 reaction test

Omissions in the first part of the complex sensorimotor

\section{Component}

$12 \quad 3$


reaction test

Average time in the second part of the complex -.492

sensorimotor reaction test

Mistakes in the first part of the complex sensorimotor .104

reaction test

Mistakes in the second part of the complex sensorimotor .246

reaction test

Average time in the first part of the complex sensorimotor -.130

reaction test

IPH level

The presented factor structure shows that the girls' IPH level is related to the average reaction time in the first part of the complex sensorimotor series: the higher the IPH level is, the more actively primary schoolgirls get engaged in work. This, however, also indicates the fact that they do not maintain the steady stimulus reaction speed throughout the whole series. Besides, unlike the boys' results, it was found that inhibitory processes in girls are not related to their IPH levels.

\section{Discussion}

The differences in the boys' and girls' data factor structures may mean that the girls have already moved into their young teenage years, which has naturally led to a change in their health attitude structure (Nikolaeva et al., 2014). The major differences are found in the behavioral (the efforts, the aspirations, and specific health-preserving and health-improving actions) and emotional (the optimal level of health anxiety) components of health-attitude. Teenagers typically demonstrate a practical component of the health attitude, whereas adults demonstrate an emotional one. Still, further research is needed to find out the objective reasons for the found differences. 


\section{Conclusions}

The factor structure for our data showed that in primary schoolchildren having low IPH levels the stimulus mistakes are inversely related to the average parameters of reaction time.

On the opposite, the primary schoolchildren having medium IPH levels showed that the number of wrong presses - made when a No Pressing sign was shown - and of wrong omissions, i.e. not pressing the button when a non-red circle appeared, does not depend on the average time in a complex sensorimotor reaction test, which means that reaction and inhibitory functions are regulated by different structures.

The process of IPH development in primary schoolboys is accompanied by a decrease in the number of wrong presses (made when a No Pressing sign appears), which indicates a better control of one's actions.

The way girls respond to participating in an activity is directly related to their IPH development. But unlike the data collected from the boys' group, the girls' inhibitory processes are not related to their IPH levels.

\section{Acknowledgments}

The reported research was funded by the Russian Foundation for Basic Research and the administration of the region of the Russian Federation, grant № 18- 413-480007. Also we would like to thank the engagement and involvement of the research participants.

\section{REFERENCES}

1. Nelson, T. D., Nelson, J. M., Mason, W. A., Tomaso, C. C., Kozikowski, C. B., \& Espy, K. A. (2019). Executive control and adolescent health: Toward a conceptual framework. Adolescent research review, 4(1), 31-43.

2. Diamond, A. (2013). Executive functions. Annual review of psychology, 64, 135-168.

3. Zysset, A. E., Kakebeeke, T. H., Messerli-Bürgy, N., Meyer, A. H., Stübl, K., LeegerAschmann, C. S., ... \& Munsch, S. (2018). Predictors of Executive Functions in Preschoolers: Findings from the SPLASHY study. Frontiers in psychology, 9, 2060.

4. Espy, K. A. (2016). The changing nature of executive control in preschool. Monographs of the Society for Research in Child Development, 81(4), 1-179.

5. Espy, K. A., Sheffield, T. D., Wiebe, S. A., Clark, C. A. C., \& Moehr, M. J. (2011). Executive control and dimensions of problem behaviors in preschool children. Journal 
of Child Psychology and Psychiatry, 52(1), 33-46. https://doi.org/10.1111/j.14697610.2010.02265.x.

6. Miyake, A., Friedman, N. P., Emerson, M. J., Witzki, A. H., Howerter, A., \& Wager, T. D. (2000). The unity and diversity of executive functions and their contributions to complex "Frontal Lobe" tasks: a latent variable analysis. Cogn. Psychol, 41, 49-100. doi: 10.1006/cogp.1999.0734

7. Garon, N., Bryson, S. E., \& Smith, I. M. (2008). Executive function in preschoolers: a review using an integrative framework. Psychol. Bull, 134, 31-60. doi: 10.1037/00332909.134.1.31

8. Rose, S. A., Feldman, J. F., \& Jankowski, J. J. (2011). Modeling a cascade of effects: The role of speed and executive functioning in preterm/full-term differences in academic achievement. Developmental Science, 14(5), 1161-1175. https://doi.org/10.1111/j.1467-7687.2011.01068.x.

9. Brydges, C. R., Fox, A. M., Reid, C. L., \& Anderson, M. (2014). The differentiation of executive functions in middle and late childhood: A longitudinal latent-variable analysis. Intelligence, 47, 34-43. https://doi.org/10.1016/j.intell.2014.08.010.

10. Meland, E., Haugland, S., \& Breidablik, H. J. (2006). Body image and perceived health in adolescence. Health Education Research, 22(3), 342-350.

11. Lee, K., Bull, R., \& Ho, R. M. (2013). Developmental changes in executive functioning. Child Development, 84(6), 1933-1953. https://doi.org/10.1111/cdev.12096.

12. Kechter, A., Black, D. S., Riggs, N. R., Warren, C. M., Ritt-Olson, A., Chou, C. P., \& Pentz, M. A. (2019). Factors in the Perceived Stress Scale Differentially Associate with Mindfulness Disposition and Executive Function among Early Adolescents. Journal of Child and Family Studies, 28(3), 814-821.

13. Gatz, J., Kelly, A. M., \& Clark, S. L. (2019). Improved Executive Function and Science Achievement for At-Risk Middle School Girls in an Aerobic Fitness Program. The Journal of Early Adolescence, 39(3), 453-469.

14. Eakin, L., Minde, K., Hechtman, L., Ochs, E., Krane, E., Bouffard, R., ... \& Looper, K. (2004). The marital and family functioning of adults with ADHD and their spouses. Journal of Attention Disorders, 8(1), 1-10.

15. Blair, C., \& Razza, R. P. (2007). Relating effortful control, executive function, and false belief understanding to emerging math and literacy ability in kindergarten. Child Development, 78(2), 647-663. https://doi.org/10.1111/j.14678624.2007.01019.x.

16. Young, S. E., Friedman, N. P., Miyake, A., Willcutt, E. G., Corley, R. P., Haberstick, B. C., \& Hewitt, J. K. (2009). Behavioral disinhibition: Liability for externalizing spectrum disorders and its genetic and environmental relation to response inhibition across adolescence. Journal of abnormal psychology, 118(1), 117.

17. Miyake, A., \& Friedman, N. P. (2012). The nature and organization of individual differences in executive functions: Four general conclusions. Current directions in psychological science, 21(1), 8-14.

18. Sawyer, A. C., Miller-Lewis, L. R., Searle, A. K., Sawyer, M. G., \& Lynch, J. W. (2015). Is greater improvement in early self-regulation associated with fewer behavioral problems later in childhood?. Developmental psychology, 51(12), 1740. 
19. Moffitt, T. E. (2012). Childhood self-control predicts adult health, wealth, and crime. In Multi-Discipl. Symp. Improv. Well-Being Children Youth.

20. Razumnikova, O. M. \& Nikolaeva, E. I. (2019) Brain inhibitory functions and the age peculiarities of cognitive activity organisation. The progress of physiology sciences, 50(1), 75-89.

21. Aron, A. R. (2011). From reactive to proactive and selective control: developing a richer model for stopping inappropriate responses. Biological psychiatry, 69(12), e55-e68.

22. Baron, A., Evangelou, M., Malmberg, L. E., \& Melendez-Torres, G. J. (2016). Protocol for a systematic review: The Tools of the Mind curriculum for improving self-regulation in early childhood: A systematic review. Philadelphia, Pennsylvannia: Campbell Collaboration.

23. Diamond, A., \& Lee, K. (2011). Interventions shown to aid executive function development in children 4 to 12 years old. Science, 333(6045), 959-964.

24. Nikolaeva, E. I., Oteva, E. A., Leutin, V. P., Maslennikov, A. B., Osipova, L. P., \& Nikolaeva, A. A. (1995). Relationships between left hemisphere predominance and disturbances of lipid metabolism in different ethnic groups. International journal of cardiology, 52(3), 207-211.

25. Novik, A. A., \& Ionova, T. I. (2007). A Guide to Examining the Quality of Life in Medicine. 2nd edition. Moscow: OLMA-PRESS, 320 p. Russ.

26. Sirgy, M. J. (2012). The psychology of quality of life: Hedonic well-being, life satisfaction, and eudaimonia (Vol. 50). Springer Science \& Business Media.

27. Nekrasova, Yu. B. (1984). Group emotional stress psychotherapy in correction of mental states of stutterers. Voprosi psychologii [Issues in Psychology], 2, 75-81. Russ.

28. Nikiforov, G. S. (2002). The Psychology of Health. A textbook. St. Petersburg: Rech', 256 p. Russ.

29. Nikolaeva, E., \& Merenkova, V. (2013). The effect of a mother's level of attachment and her emotional intelligence on a child's health during its first year of life. Psychology, 4(05), 483.

30. Nikolaeva, E. I., \& Merenkova, V. S. (2017). An inner picture of health as a factor in changing a child's behavior to health-promoting behavior. Psychology in Russia, 10(4), 44.

31. Nikolaeva, E., Merenkova, V., \& Trenin, E. (2014). The preschoolers' inner health picture. Global Journal on Advances in Pure \& Applied Sciences, 4, 61-65.

32. Nikolaeva, E. I., \& Yavorovich, K. N. (2013). The Peculiarities of Qualitative and Reaction Characteristics of Sensorimotor Integration in Young Men and Young Girls Having Different Intensity Degrees of Lateral Features. The Issues of Psychology, 5, p.133.

33. Vergunov, E. G., Nikolaeva, E. I., Balioz, N. V., \& Krivoshchekov, S. G. (2018). Lateral Preferences as Possible Phenotypic Predictors of the Reserves of the Cardiovascular System and the Features of Sensorimotor Integration in Climbers. Human physiology, 44(3), 320-329. 
34. Nikolaeva, E. I., Fedoruk, V. I., \& Zacharina, E. Yu. (2014). The health promoting and health forming behavior in kindergarten. Saint-Petersburg: DetstvoPress. Russ.

35. Bernardi, A. (2019). The capability approach and organizational climate as tools to study occupational health and safety. Insights into Regional Development 1(2), 155-169.

36. Chistobaev, A. I., Semenova, A. Z., \& Grudtsyn, N. A. (2018). Dynamics and strategic directions of public health preservation in Russian Federation. Entrepreneurship and Sustainability Issues, 6(3), 1180-1192.

37. Al-Hashimy, H. N. H., Hamoud, A. K., Hussain, F. A. (2019). The Effect of Not Using Internet of Things in Critical life Situations in the Health Field and the Effect on Iraqi Profitability: Empirical Study in Basra. Journal of Southwest Jiaotong University, 54(4). http://jsju.org/index.php/journal/article/view/316

\section{SOBRE OS AUTORES:}

\section{V.S. Merenkova}

Department of psychology and psychophysiology, Bunin Yelets State University, YelSU, Kommunarov str., 28.1. Yelets, 399770, Russian Federation. E-mail: vs.merenkova@bk.ru

(iD) http://orcid.org/0000-0003-1550-3746

\section{O.E. Elnikova}

Department of psychology and psychophysiology, Bunin Yelets State University, YelSU, Kommunarov str., 28.1. Yelets, 399770, Russian Federation. E-mail: oe.elnikova@ bk.ru

(iD http://orcid.org/0000-0001-7904-3705

Recebido em: 13 de setembro de 2019

Aprovado em: 26 de agosto de 2019

Publicado em: 09 de dezembro de 2019 